\title{
Scenarios of Palm-Oil Biodiesel in the Mexican Transportation Sector
}

\author{
Jorge M. Islas S. ${ }^{1, a^{*}}$, Genice K. Grande A. ${ }^{1, b}$ and Fabio L. Manzini Poli ${ }^{1, c}$ \\ ${ }^{1}$ Instituto de Energías Renovables, Universidad Nacional Autónoma de México, México

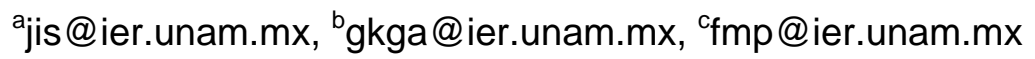

Keywords: palm-oil biodiesel; scenarios; Mexican transportation sector; GHG mitigation; cost-benefit analysis

\begin{abstract}
This work analyses the environmental and economic feasibility of producing palm oilbased biodiesel in Mexico in order to substitute of diesel fuel consumption using B5 first and B10 to 2031 in the transportation sector. Two scenarios were created by projecting demand and costs for biodiesel as well as greenhouse gases emissions reduction and area requirements. In the economic section, the cost-benefit analysis of biodiesel and the mitigation costs of carbon dioxide were estimated. This work shows that Application of tax incentives could make biodiesel competitive against diesel.
\end{abstract}

\section{Introduction}

Biodiesel has been used in some countries as a substitute for diesel fuel in the transportation sector. In 2017 the production of biodiesel was increased by 82\% compared to the year 2016 in the European Union. Countries with the highest production of rapeseed-based biodiesel are Germany 4,005 K t/year (151 $\mathrm{PJ}^{1}$ ), Spain 3,398 K t/year (128 PJ), and The Netherlands 2,505 K t/year (95 PJ) [1]. Production of biodiesel in United States mainly derived from soybean oil was 9,275 K t/year (351 PJ) in 2016, which represented an increase of $40 \%$ compared to the year 2015 [3].

Mexico has the problem of declining proven oil reserves and official sources estimated them in 8.5 years [4]. On the other hand, the use of energy generates a large amount of greenhouse gases (GHG), so in 2015 at the country level were emitted 442.3 million tons of $\mathrm{CO}_{2}\left(\mathrm{Mt} \mathrm{CO}_{2}\right)$ of which $33 \%$ were generated by the road transportation sector; $7 \%$ corresponds to diesel vehicles [5].

In 2016, internal demand of diesel fuel in the Mexican transportation sector accounted nearly $26 \%$ in relation to the other fuels and grew at an average annual growth rate of $2 \%$ in the last 10 years [6].

The use of palm oil in Mexico as B5 and B10 can help reduce $\mathrm{CO}_{2}$ emissions and reduce dependence on fossil fuels in the transportation sector. Given that the main raw material is vegetable oil, biodiesel is becoming a notable factor for promoting the regional development in Mexico.

In this work, we develop scenarios to use B5 and B10 in the Mexican transportation sector and we evaluate these scenarios in terms of a cost-benefit analysis, the amount of carbon dioxide $\mathrm{CO}_{2}$ reduced and the area cultivated with oil palm. Likewise, $\mathrm{CO}_{2}$ mitigation costs were estimated, and the impact of tax incentives on the economic feasibility of biodiesel was analyzed.

\section{Methodology}

To develop this work the following steps are made base on [7]:

\footnotetext{
${ }^{1}$ The calorific value of biodiesel considered in this article is $37.8 \mathrm{MJ} / \mathrm{Kg}$ [2]
} 
A. The trend scenario corresponds to the scenario based on diesel while the alternative scenario was developed to use in a large scale the biodiesel in the Mexican transport sector.

B. Scenarios were built and simulated using LEAP (Long-range Energy Alternative Planning System [8]).

C. In this study the base year is 2005 , due to the data were available for that year meanwhile the period of analysis was until 2031

D. The energy consumption was obtained in the trend scenario and the same energy consumption was considered for the alternative scenario.

E. For the alternative scenario oil palm-cultivated area requirements were obtained.

$\mathrm{F}$. The $\mathrm{CO}_{2}$ emissions were calculated for each of the analyzed scenarios.

G. The overall and mitigation costs of the alternative scenario were calculated.

H. Finally, the economic feasibility of alternative scenario is analyzed considering the implementation of tax incentives.

\section{Scenarios construction}

\section{Trend scenario}

The establishment of the trend scenario were conducted based on the followings two components:

1. Evolution of diesel vehicle fleet: The first step consists of estimating the evolution of vehicle fleet in the reference year, based on the existing stock, sales and vehicles that will be retired over the analysis period. This fleet was divided into the following categories: a) heavy-duty trucks, and b) passenger vehicles and private cars. The statistics on heavy-duty trucks reported at federal level are considered as a good approximation to depict the size of this fleet at national level. According to these, $97 \%$ of diesel-powered vehicle fleet was composed of heavy-duty trucks, while passenger vehicles accounted for slightly over $2 \%$. The remainder was private cars. The second step consists of assigning a life cycle profile for each vehicle category so that the distribution of vehicles of different ages can be described in the reference year. According to our results the heavy-duty fleet is very old, since $78 \%$ of its vehicles are over 10 years old. In the 2006-2031 period, the growth of vehicle fleet is determined by sales and the survival of vehicles as they get older. Vehicle sales totaled 450 thousand for heavyduty trucks [9], 12,500 for passenger vehicles [10], and 1,000 for private cars [11] in the reference year. With regard to the trend in vehicle sales, it is considered an average annual growth rate of $4 \%$ for both, heavy-duty and passenger vehicles, according to their historical growth [9]. Thus, it is expected that heavy-duty and passenger vehicles continue to grow at their historical growth rates; however, it is foreseen a further expansion of vehicle sales, owing to the replacement of some units of the existing vehicle stock, which is mostly composed of old units. In order to gradually replace existing vehicle stock, a survival profile describing the retirement of old vehicles is used. This profile represents the percent survival of vehicles as they get older as well as the percent share of vehicles that gradually will be retired from the existing vehicle stock in the country and always takes a percent share of $100 \%$ during the first year. This profile can be expressed by the following function:

$$
F(t)=F(t-1) e^{t K}
$$

Where $\mathrm{F}$ is the fraction of surviving vehicles and $\mathrm{t}$ is the age in years of the vehicle. 


$$
K=\frac{\ln F(t)-\ln (F(t-1))}{t}
$$

K represents a decreasing rate of the existing vehicle stock in time t, and takes a negative value.

The survival profile of heavy-duty trucks and passenger vehicles was represented by these equations. In both cases $\mathrm{K}$ was obtained by averaging calculations for 4 years, resulting in $\mathrm{K}=-0.01$ and $\mathrm{K}=-0.04$ for heavy-duty trucks and passenger vehicles, respectively. For private cars, and due to the fact that related information was not available, the value of K was assumed -0.0236, which corresponds to the one reported for gasoline vehicles in Mexico [12].

Once the survival profiles and existing stocks in the reference year as well as the annual growth in future sales have been obtained for each vehicle category, the trend in vehicle fleet is simulated using LEAP for the analyzed period. Thus, for each year of analysis, annual sales are summed to the existing vehicle stock in the reference year, while the number of vehicles that will be retired from this stock is subtracted according to the survival profile of each vehicle category.

According to our results diesel vehicle fleet would reach 20.45 million in the year 2031, of which 16.5 million corresponds to heavy-duty trucks, 480 thousand to passenger vehicles, and 3.3 million to private cars, respectively (see Figure 1).

2. Estimation of diesel demand: In order to calculate the total annual diesel fuel demand in the transportation sector it is required to estimate for each vehicle category the fuel consumption of existing vehicle fleet in the year t. This is obtained from an estimate of the number of existing vehicles in the year t, their average annual mileage (in kilometers), and the average annual diesel consumption.

Fuel consumption of heavy-duty trucks and passenger vehicles was calculated based on data reported for these vehicle categories in the USA [13]. The annual mileage (in kilometers) was calculated using the average value reported in the 2002 National Inventory of Emissions. Based on these data, energy consumption for each vehicle category was calculated in LEAP by multiplying the existing vehicle stock in the year t, the annual mileage (in kilometers), and the fuel consumption. In trend scenario, the vehicle fleet would consume 1,543 PJ by the year 2031. 


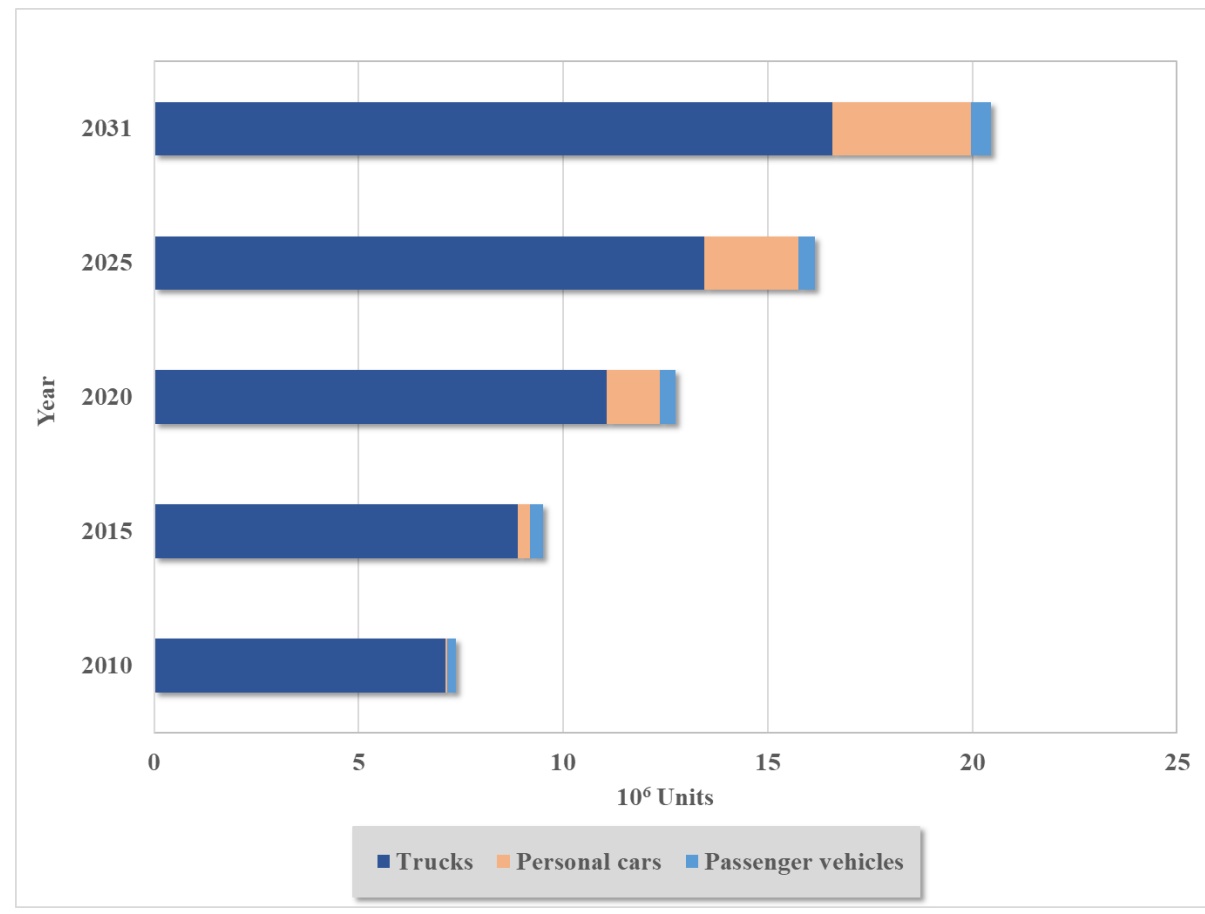

Fig. 1. Evolution of diesel-powered vehicle fleet in the Mexican transportation sector [7].

\section{Alternative scenario}

The alternative scenario considers the same evolution in vehicle fleet at national level that the Trend Scenario and aims at identifying the main parameters related to the substitution of diesel fuel in Mexico. The main assumptions for the construction of this scenario are:

- It considers the use of B5 and B10, which implies the massive use of palm oil-based biodiesel.

- The plantations and infrastructure for production and distribution of biodiesel have been developed in the country. This considers a potential for growing oil palm, taking account of requirements such as water, temperature, soil and fertility have an optimal gross potential of 2.5 million hectares (Ha) in Mexico [14] and a yield of 3,239 liters (L) per hectare or 20 tons of fresh fruit bunches (FFB) per Ha [7].

- The calorific value of biodiesel is lower $13 \%$ in mass terms than that of diesel fuel [15].

- It considers that the emissions of carbon dioxide $\left(\mathrm{CO}_{2}\right)$ for biodiesel (B100) are neutral.

- It considers that biodiesel is produced in plants with a capacity of 38 million of L per year, which requires investment costs of $\$ 12.5$ million [7].

- The structure of operating costs used in this article, in terms of USD/L of biodiesel is shown in Figure 2. As can be seen in this figure, most of the costs per liter of biodiesel are occupied by raw material (79\%) and the rest costs such as services and fuels, operation and maintenance and other costs (21\%). It is important to note that there is income from the sale of glycerol as a co-product that can represent a benefit of $17 \%$ of the unit cost per liter of palm oil biodiesel, which has a cost of 0.380 USD/L.

- This study considers a discount rate of $10 \%$. 


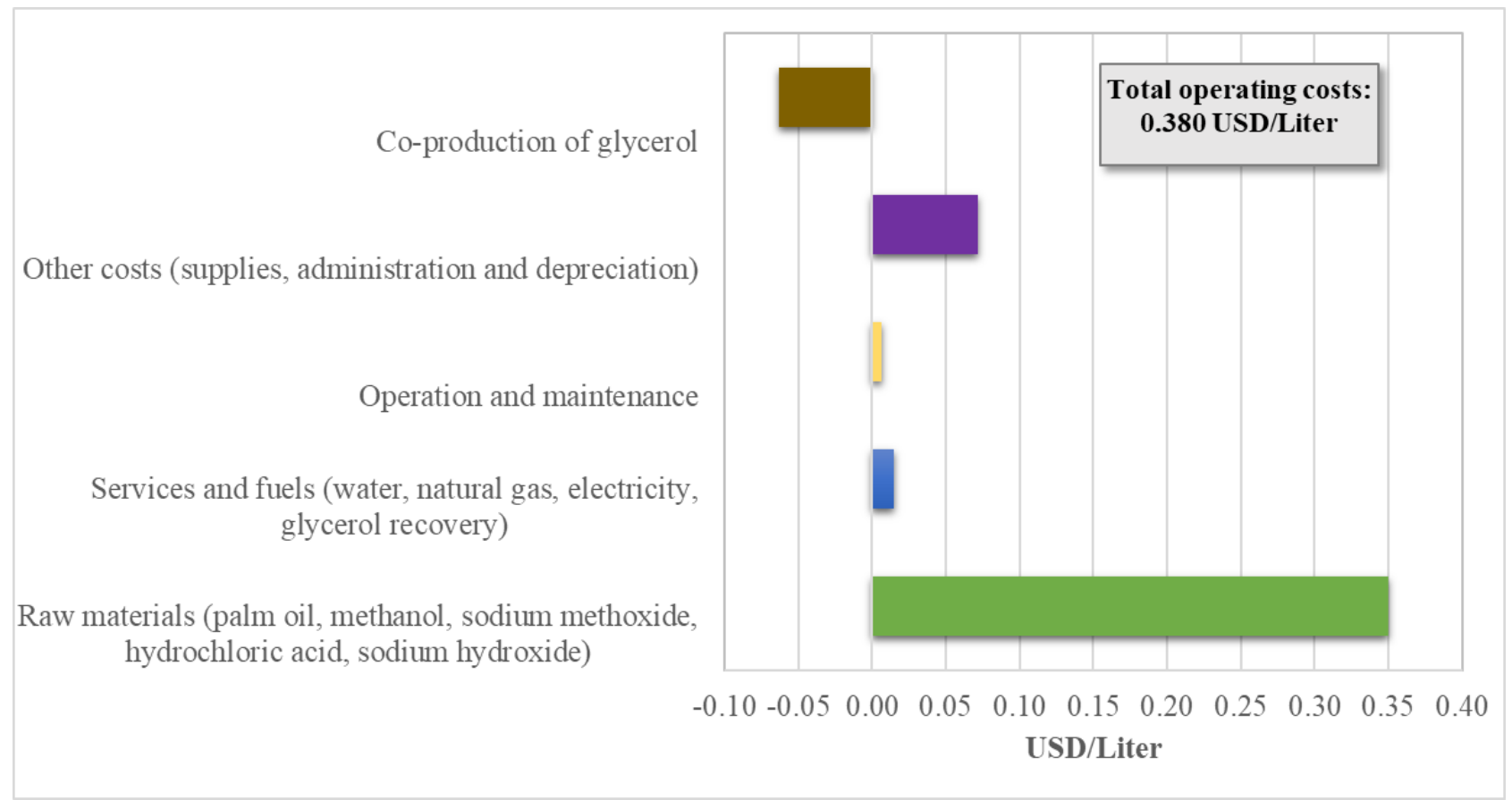

Fig. 2. Structure of operating costs for Palm-Oil biodiesel production (USD/L) [7].

\section{Results}

The biodiesel replaces 9\% of diesel fuel consumption of the transport sector in the alternative scenario in 2031. This represents $8 \%$ of total energy required in the period analysis (see Figure 3).

The small biodiesel plants need a production capacity of 133.7 million of L/year by 2031 that means 113 biodiesel plants would be required. The cumulative investment costs of these plants would be approximately $\$ 7882$ million.

To meet this scenario, it is required approximately 1 million hectares of cultivated area to satisfy the palm-oil biodiesel demand. This cultivated area is far below of good resource potential equivalent to 2.5 million of $\mathrm{Ha}$. These results indicate that the proposed alternative biodiesel scenario would be enough to meet the palm-oil biodiesel demand of Mexican road transport sector.

\footnotetext{
${ }^{2}$ In this article the monetary unit is US dollar of year 2007.
} 


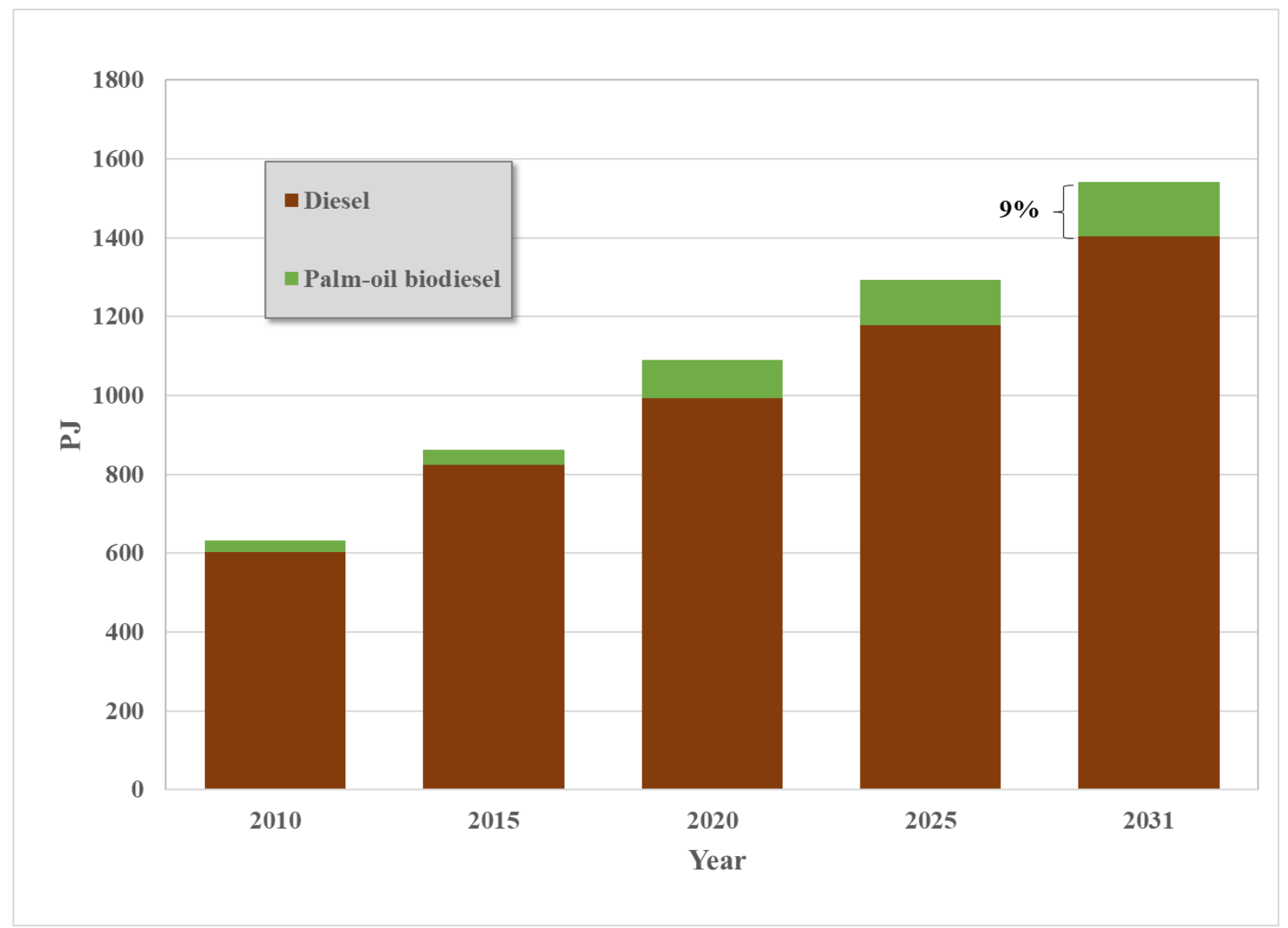

Fig. 3. Palm-oil biodiesel and diesel demand in alternative scenario [7].

The $\mathrm{CO}_{2}$ emissions would be reduced by about 10 million tons by 2031. This reduction would also account for $9 \%$ in relation to trend scenario. The cumulative reduction could arrive to 148 million tons of $\mathrm{CO}_{2}$ emissions (see Figure 4), which represents a total reduction of $8 \%$.

The results show that biodiesel costs, when compared with the costs of diesel fuel, would represent overall costs of 2.3 billion dollars (BUSD) (4.7 BUSD of avoided costs of diesel fuel vs 7 BUSD of the costs of using biodiesel). Finally, mitigation costs would total 16 USD/ton of $\mathrm{CO}_{2}$. Nevertheless, we found that if diesel price and biodiesel prices, this last one exempting the Special Tax on Production and Services (IEPS), are compared, the massive use of biodiesel would lead to a net benefit of 1.24 BUSD.

\section{Conclusions}

The potential to produce oil palm in México, is more than enough to cover the needs of B5 and B10 of the alternative scenario.

$\mathrm{CO}_{2}$ emissions would reach cumulative reductions of 148 million tones that means $8 \%$ of the trend scenario.

Finally, the cost-benefit analysis points out that the substitution of diesel fuel for palm oilbased biodiesel is feasible when a tax-exemption policy (e.g. exemption of IEPS) is implemented. 


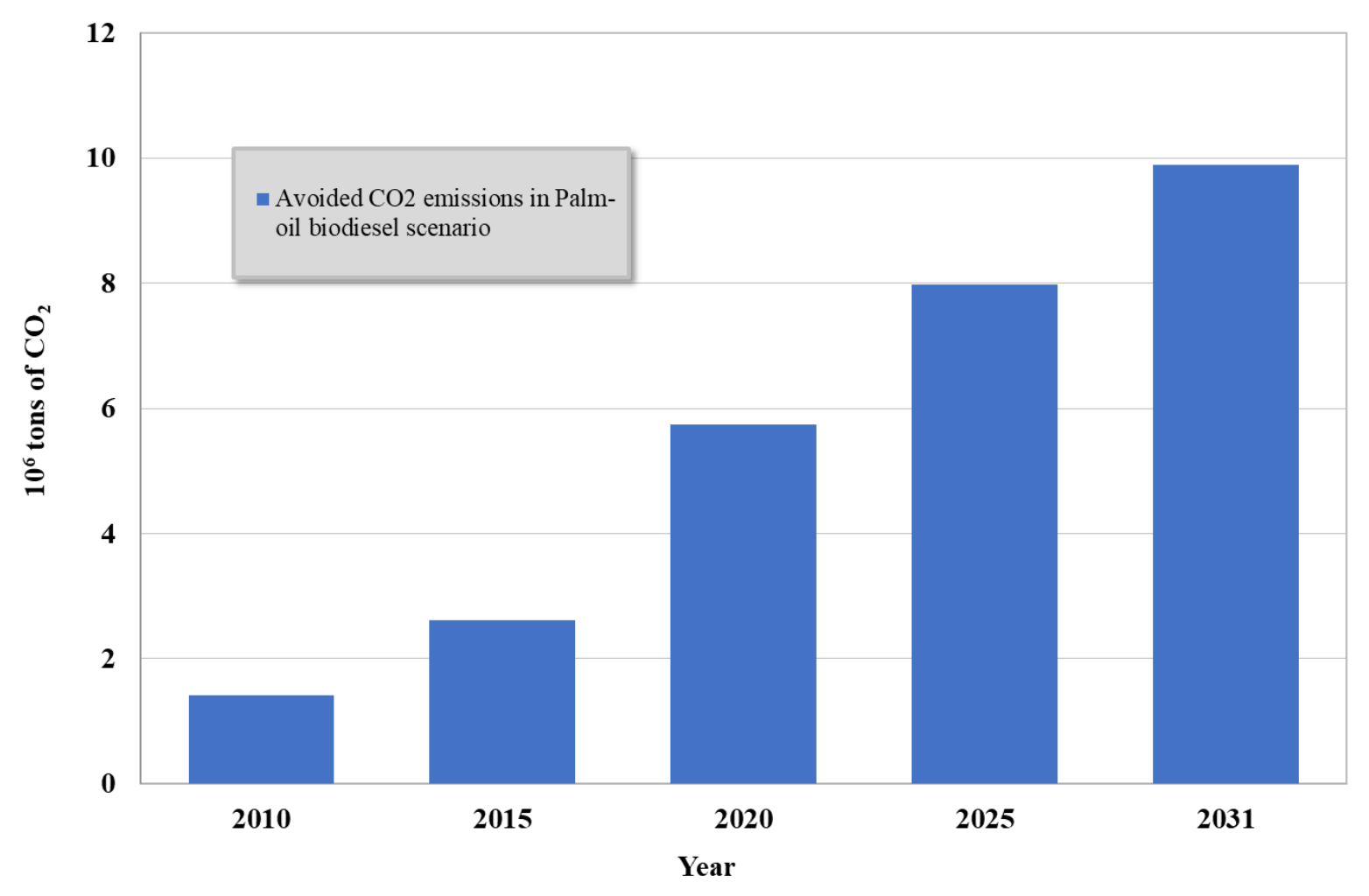

Fig. 4. Avoided CO2 emissions under palm-oil biodiesel scenario [7].

\section{Acknowledgments}

The authors acknowledge Project CEMIE-BIO "Clúster Biocombustibles Sólidos - Línea 4 Sustentabilidad y Políticas Públicas de Biocombustibles Sólidos, Fondo de Sustentabilidad Energética SENER-CONACYT, for the partial financing of this work.

\section{References}

[1] European Biodiesel Board (EBB), Statistics, The EU biodiesel industry, Available at: http://www.ebb-eu.org/stats.php, 2018.

[2] D. Pimentel, Global economic and environmental aspects of Biofuels. Ed. Taylor \& Francis Group, 2012, pp. 428.

[3] National Biodiesel Board (NBB), Available at: http://www.biodiesel.org, 2018.

[4] Petróleos Mexicanos (PEMEX), Reservas 1P al primero de enero de 2018, PEMEX, Mexico.

[5] International Energy Agency (IEA), CO2 emissions from fuel combustion. Paris, France, OECD/IEA (2017). https://doi.org/10.1787/804a05bf-en

[6] Secretaría de Energía (SENER), Balance Nacional de Energía 2016, SENER, Mexico (2017). 
[7] I. Lozada, J. Islas, G. Grande, Environmental and economic feasibility of palm oil biodiesel in the Mexican transportation sector, Renew Sust Energ Rev 14 (2010) 486-492. https://doi.org/10.1016/j.rser.2009.06.034

[8] C.G. Heaps Long-range energy alternatives planning (LEAP) system. [Software version 2008.0.0.33], Stockholm Environment Institute, USA (2008).

[9] Instituto Nacional de Estadística y Geografía (INEGI), Balanza Comercial de México. INEGI, Mexico (2015).

[10] Information on: http://www.anpact.com.mx.

[11] Information on: http://www.volkswagen.com.mx.

[12] F. Manzini, Inserting renewable fuels and technologies for transport in Mexico City Metropolitan Area. International Journal of Hydrogen Energy 31 (2007), pp. 335-327. https://doi.org/10.1016/j.ijhydene.2005.06.024

[13] R. Giannelli, E. Nam, Y. Helmer, et al., Heavy-duty diesel vehicle fuel consumption modeling based on road load and power train parameters, United States. Paper offer \#:05cv-3 (2005). https://doi.org/10.4271/2005-01-3549

[14] Instituto Nacional de Investigaciones Forestales, Agrícolas y Pecuarias (INIFAP). Tecnología para la producción de palma de aceite Elaeis guineensis Jacq. en México, 2a ed. INIFAP, México (2006)149. https://doi.org/10.24850/j-tyca-2017-03-04

[15] M. Canakci, Combustion characteristics of a turbocharged DI compression ignition engine fueled with petroleum diesel fuels and biodiesel, Bioresource Technology 98 (2007) 1175-1167. https://doi.org/10.1016/j.biortech.2006.05.024 